\title{
II. Der Mikrococcus der Sputumsepticaemie. (M. Pasteuri, Sternberg.)
}

\author{
Von
}

Dr. George M. Sternberg, Major und Surgeon, U. S. Army.

Nit grossem Interesse habe ich die kürzlich erschienenen Abhandlungen A. Fränkel's') über die biologischen Charaktere eines von mir im September 1880 entdeckten pathogenen Mikrococcus gelesen. Ich nannte ihn damals Mikrococcus Pasteuri, wie meine Abhandlung im American Journal of the medical Sciences (Julinummer 1885) zeigt, die geraume Zeit vor Fränkel's Untersuchungen publicirt wurde. In meinem obenerwähnten Aufsatz machte ich nur den Fehler, anzunehmen, dass der betreffende Mikrococcus identisch sei mit dem sogenannten "Pneumococcus" von Friedländer. Zur Zeit, als ich meine Abhandlung schrieb, hatte ich den Bacillus Friedländer's noch nicht gesehen. Als ich aber im November 1885 Gelegenheit hatte, denselben im Laboratorium von Professor Koch näher zu untersuchen, erkannte ich sofort Verschiedenheiten in der Art des Wachsthums in Cultur-Medien, was mir klar machte, dass die beiden Organismen, obgleich ähnlich in ihrer Morphologie, doch verschiedene Species seien.

In einem Aufsatz, den ich im Am. Journ. of the med. Sciences Juli 1885 veröffentlichte, habe ich die nöthige Verbesserung gemacht und meinen Fehler folgendermassen erklärt:

"Meine Folgerung stïtzte sich hauptsächlich auf Untersuchungsergebnisse, welche das Vorhandensein von M. Pasteuri im pneumonischen Sputum zeigten. Denn ich konnte nicht zweifeln, dass der Organismus, welchen ich in diesem Material gefunden, durch Inoculation bei Kaninchen und durch Culturen in flüssigen und festen Medien geprüft hatte, identisch sei mit dem Mikrococcus, welchen ich so oft in Reinculturen durch Einspritzung meines eigenen Speichels unter die Haut von Kaninchen erhalten hatte. Noch immer bin ich ïberzeugt, dass dies wahr ist und ebenso, dass in den Experimenten Salomon's und Salvioli's mein M. Pasteuri und nicht Friedländer's Bacillus der Organismus war, welcher im Blute von Kaninchen nach der Einspritzung von pneumonischem Exsudat gefunden wurde." (l. c. p. 123.)

In meinem Aufsatz vom Juli 1885 (Am. Journ. of the med. Sciences) einige Zeit vor dem Erscheinen von Fränkel's erster Abhandlung, spreche ich klar und deutlich meine Ueberzeugung aus, dass dieser Organismus ätiologische Beziehung zur croupösen Pneumonie hat, wie aus folgendem Citate ersichtlich ist:

1) Zeitschrift für klin. Med. Band X, H. 5 und 6, 1886. Ibid. Band XI. H. 5 und 6. 
„Es scheint ausserordentlich wahrscheinlich zu sein, dass dieser Mikrococcus bei der Aetiologie der croupösen Pneumonie betheiligt ist und dass die infectiöse Natur dieser Krankheit dem Vorhandensein dieses Coccus in dem fibrinösen Exsudat in den Lungenalveolen zuzuschreiben ist. Doch kann dies nicht als definitiv entschieden betrachtet werden durch die Experimente, welche bisher an niederen Thieren vorgenommen wurden. Das fortwährende Vorhandensein dieses Mikrococcus in den Mundsecretionen gesunder Menschen deutet an, dass noch ein andrer Factor nöthig ist zur Entwicklung einer Pneumonie. Es ist nun wahrscheinlich, dass dieser Factor thätig ist, indem er die vitale Widerstandskraft der Lungengewebe herabsetzt und sie so für die Angriffe des Mikrococcus empfänglich macht. Diese Vermuthung befähigt uns, die Entwicklung zahlreicher: Fälle von Pneumonie zu verstehen, die nicht auf äusserliche Infection zurückgefïhrt werden können. Da der Keim fortwährend vorhanden ist, kann Autoinfection nur vorkommen, wenn die Lebenskraft der Gewebe durch Alkoholismus, Vergiftung durch Cloakengase, $\mathrm{Zu-}$ sammengedrängtsein der Menschen oder durch irgend einen anderen schwächenden Einfluss unter den Grad der Widerstandsfähigkeit herabgesetzt worden ist." (l. c. p. 122).

Fränkel's ausgedehnte und sorgfältig geleitete Untersuchungen bestärken die Ansicht sehr, dass dies wirklich der wahre Pneumonieorganismus ist. Wenn dies erst vollständig erwiesen ist, dann wird man ibn mit Recht wohl Mikrococcus crouposae pneumoniae nennen. Bis dies jedoch völlig geschehen ist, wäre es recht, dass er den Namen führt, den ich ihm gegeben habe.

Ich beobachtete den betreffenden Organismus zuerst im Blute eiues Kaninchens, welches an den Folgen einer subcutanen Einspritzung meines Speichels im September 1880 starb. Pasteur's berühmtes Experiment mit dem Speichel eines Kindes, welches iu einem Pariser Hospital an der Hydrophobie starb, wurde erst im December desselben Jahres gemacht. (11. Dec.)

Die Thatsache, dass mein Speichel einen Mikroorganismus enthielt voll solch entschiedener pathogener Kraft, erregte sofort mein Interesse, und im Januar 1881 begann ich ein experimentelles Studium, um den physiologischen Charakter dieses Mikrococcus zu bestimmen. Die Resultate dieser Untersuchungen finden sich in einer Abhandlung verzeichnet, die im Bulletin of the National Board of Health (Vol. II, 1881) und später in den Studies from the biological laboratory, Johu Hopkins University (Vol. II. No . 2, 1881) veröffentlicht wurde. Die Morphologie des Organismus ist in der letztgenannten Veröffentlichung meines Aufsatzes durch Mikrophotographieen illustrirt. In demselben Journale befindet sich ancl ein Bericht über ausgedehnte Experimente, welche angestellt wurden, um die vitale Widerstandskraft dieses Mikrococcus gegenïber verschiedenen chemischen Agentien zu bestimmen. (op. cit. Vol. II., No. 2, p. $201-212$ ).

Im folgenden Jahre (1882) führte ich meine Experimente weiter und veröffentlichte mehrere kürzere Abhandlungen über die physiologischen Eigenschaften dieses Organismus. (The Medical Times, Philadelphia, Sept. 9 und Nov. 4; The Medical News, Philadelphia, July 8 und Sept. 16: Am. Journ. med. Sciences. Juli 1883 p. 69-76). Im Jahre 1883 machte ich weitere Experimente über die Wirkung chemischer Reagentien auf den betreffenden Organismus (Am. J. med., Sc. April 1883 p. 321-343).

In meinem Buche "Bacteria", New-York 1884, gebe ich einen Bericht über die Resultate meiner bis dahin ausgeführten Untersuchungen unter dem Titel ,Septicaemia in Rabbits ${ }^{6}$ (p. 355-376).

Als ich meine ersten Experimente anstellte, hatte uns $\mathrm{Koch}$ noch nicht gelehrt, feste Culturmedien zu gebrauchen. Meine Culturen wurden mit flüssigen Medien, in hermetisch verschlossenen Röhren gemacht. Meine Methode, welche in meinem erwähnten Buche vollständig beschrieben ist, gewährte mir vollste Reinheit meiner Culturen. Seitdem habe ich diesen Mikrococcus wiederholt in festen Medien cultivirt (Blutserum und Agar Agar).

Fränkel sagt in seiner letzten Abhandlung über diesen Organismus, dass er ihn zuerst reincultivirt habe. Unter der Bezeichnung Pneumonie-Mikrococcus ist hier und im Folgenden ausschliesslich der von mir zuerst rein cultivirte, sowie hinsichtlich seiner biologischen Eigenschaften eingehend studirte ovaläre Doppelcoccus verstanden." (A. Fränkel in Zeitschrift für klinische Medicin Bd. XI. S. 437).

Flügge beschreibt ihn in der zweiten Auflage seines werthvollen Werkes: "Die Mikroorganismen" unter den Namen "Bacillus septicus sputigenus (Fränkel).

Angesichts all dieser Thatsachen hielt ich es für angezeigt, auch in deutscher Sprache die in vorstehenden Zeilen enthaltenen Berichte über die Geschichte unserer Kenntniss dieses interessanten pathogenen Organismus bekannt zu machen. 